\title{
Solution Phase Halide Exchange and Targeted Annealing Kinetics in Lead Chloride Derived Hybrid Perovskites
}

Vivek Thampy and Kevin H. Stone*

SLAC National Accelerator Laboratory, 2575 Sand Hill Road, Menlo Park, CA, USA

*Email - khstone@slac.stanford.edu

\section{$\underline{\text { Supplemental Information }}$}

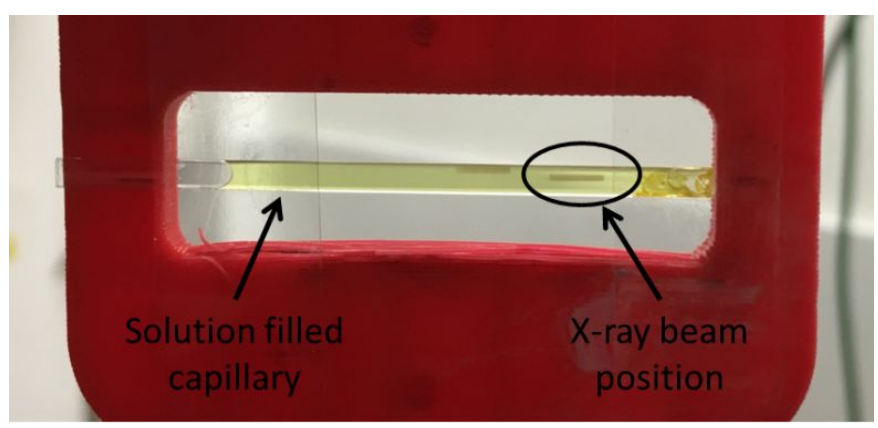

Figure S1 - Picture of solution filled rectangular capillary used for EXAFS measurements. The capillary was filled with solution and mounted in air before being placed in a helium purged atmosphere for measurement. The X-ray beam position and relative size can be seen by the dark grey region on the capillary. This is caused by the generation of color centers in the glass capillary. No beam induced changes to the solution were observed during measurement.

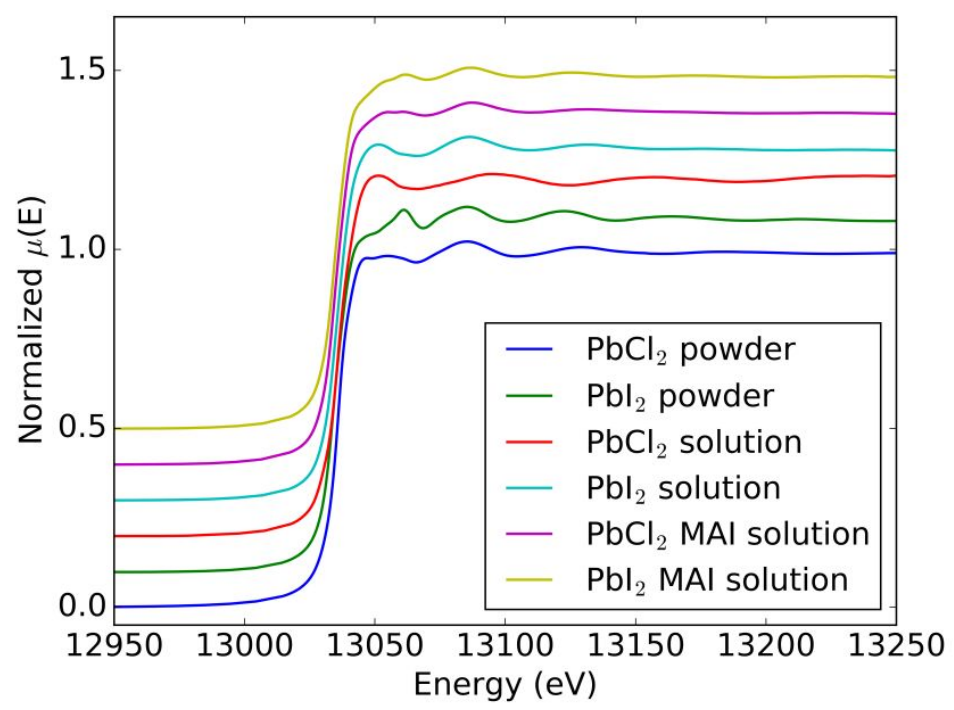

Figure S2 - X-ray absorption near edge structure (XANES) for the $\mathrm{Pb} \mathrm{L}_{\mathrm{III}}$-edge for the samples considered in this work. 

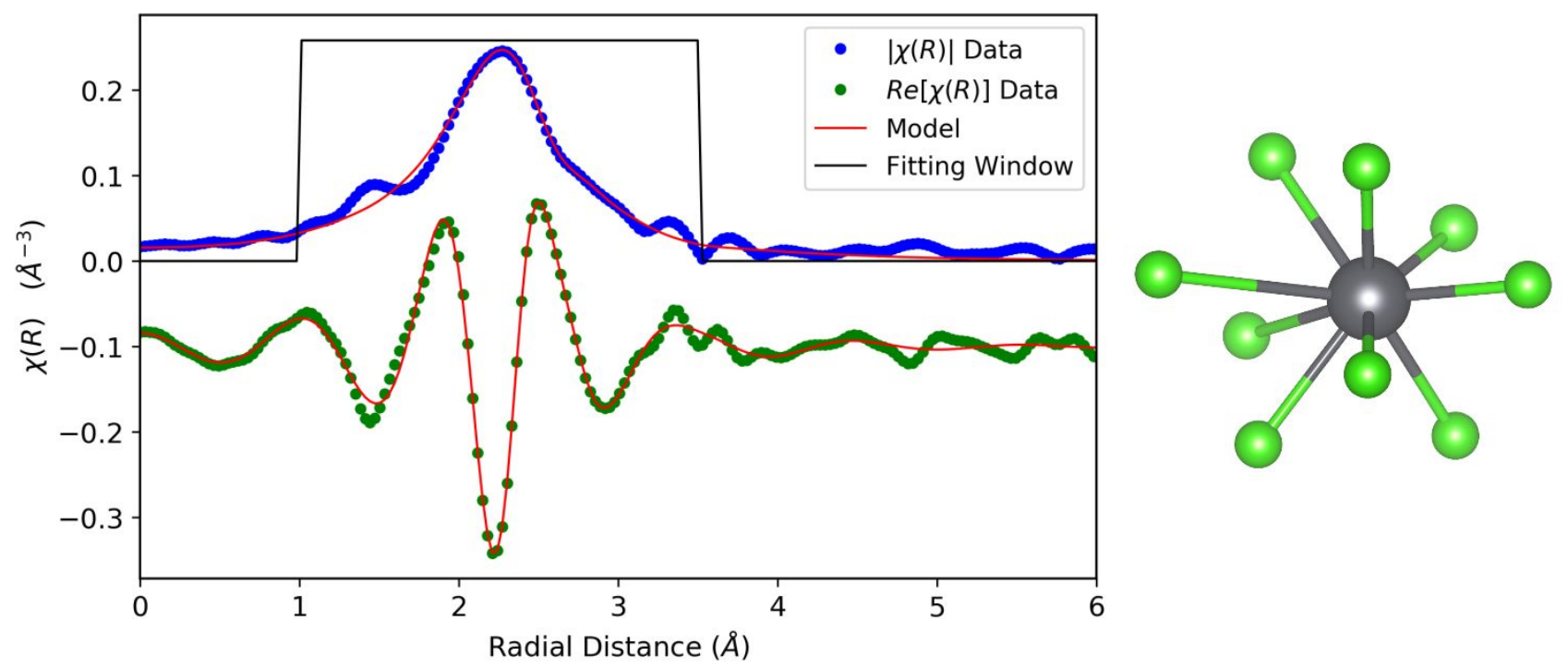

Figure S3 - Magnitude and real part of the Fourier transform of the $\mathrm{Pb} \mathrm{L}_{\mathrm{III}}$-EXAFS for $\mathrm{PbCl}_{2}$ powder (left) and schematic of local coordination of $\mathrm{Pb}$ species with $9 \mathrm{Cl}$ atoms (right).

\begin{tabular}{|c|c|c|c|c|c|c|c|}
\hline Coordinating Atom & $\mathrm{N}$ & $\mathrm{S}_{0}{ }^{2}$ & $\sigma^{2}$ & $\mathrm{E}_{0}$ & $\Delta \mathrm{R}$ & Reff & $\mathrm{R}$ \\
\hline $\mathrm{C} 11$ & 2 & $0.65 \pm 0.26$ & $0.0132 \pm 0.0027$ & $-2.59 \pm 2.40$ & $0.046 \pm 0.035$ & 2.784 & $2.830 \pm 0.035$ \\
\hline $\mathrm{Cl} 2$ & 5 & $0.65 \pm 0.26$ & $0.0279 \pm 0.0101$ & $-2.59 \pm 2.40$ & $-0.072 \pm 0.100$ & 3.01780 & $2.980 \pm 0.100$ \\
\hline $\mathrm{Cl} 3$ & 2 & $0.65 \pm 0.26$ & $0.0406 \pm 0.0288$ & $-2.59 \pm 2.40$ & $-0.072 \pm 0.079$ & 3.67460 & $3.60217 \pm 0.079$ \\
\hline
\end{tabular}

EXAFS fitting summary:

k range: $3-14$

Number of variables: 8

$\chi^{2}=1305.98$

$\chi_{\text {Reduced }}^{2}=140.08$

$\mathrm{R}$-factor $=0.0170$ 

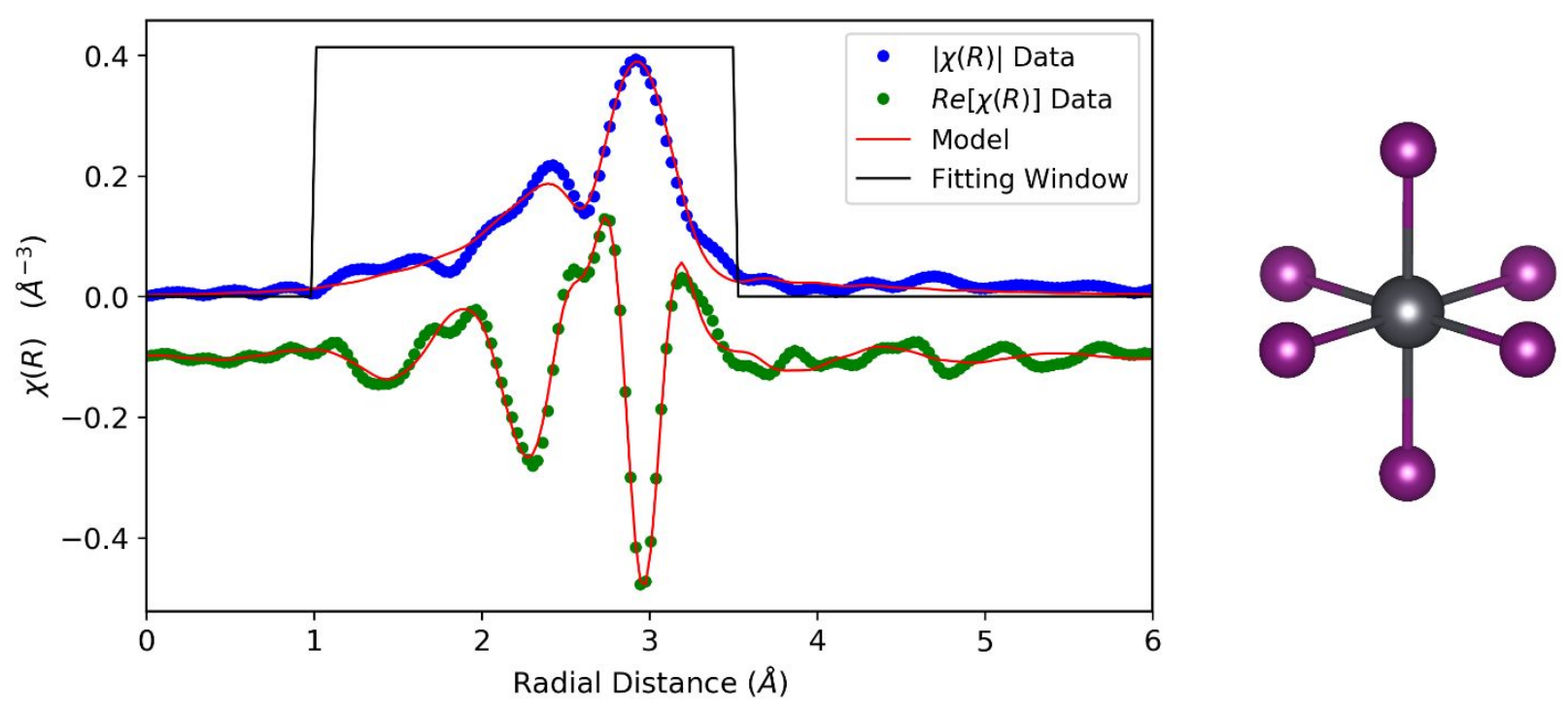

Figure S4 - Magnitude and real part of the Fourier transform of the $\mathrm{Pb} \mathrm{L}_{\mathrm{III}}-\mathrm{EXAFS}$ for $\mathrm{PbI}_{2}$ powder (left) and schematic of local coordination of $\mathrm{Pb}$ species with $6 \mathrm{I}$ atoms (right).

\begin{tabular}{|c|c|c|c|c|c|c|c|}
\hline Coordinating Atom & $\mathrm{N}$ & $\mathrm{S}_{0}{ }^{2}$ & $\sigma^{2}$ & $\mathrm{E}_{0}$ & $\Delta \mathrm{R}$ & $\operatorname{Reff}$ & $\mathrm{R}$ \\
\hline $\mathrm{I} 1$ & 6 & $0.83 \pm 0.05$ & $0.0152 \pm 0.0008$ & $-2.20 \pm 0.41$ & $-0.041 \pm 0.006$ & 3.216 & $3.175 \pm 0.006$ \\
\hline
\end{tabular}

\section{EXAFS fitting summary:}

k range: $3-14$

Number of variables: 4

$\chi^{2}=6921.96$

$\chi_{\text {Reduced }}^{2}=589.54$

$\mathrm{R}$-factor $=0.0228$ 

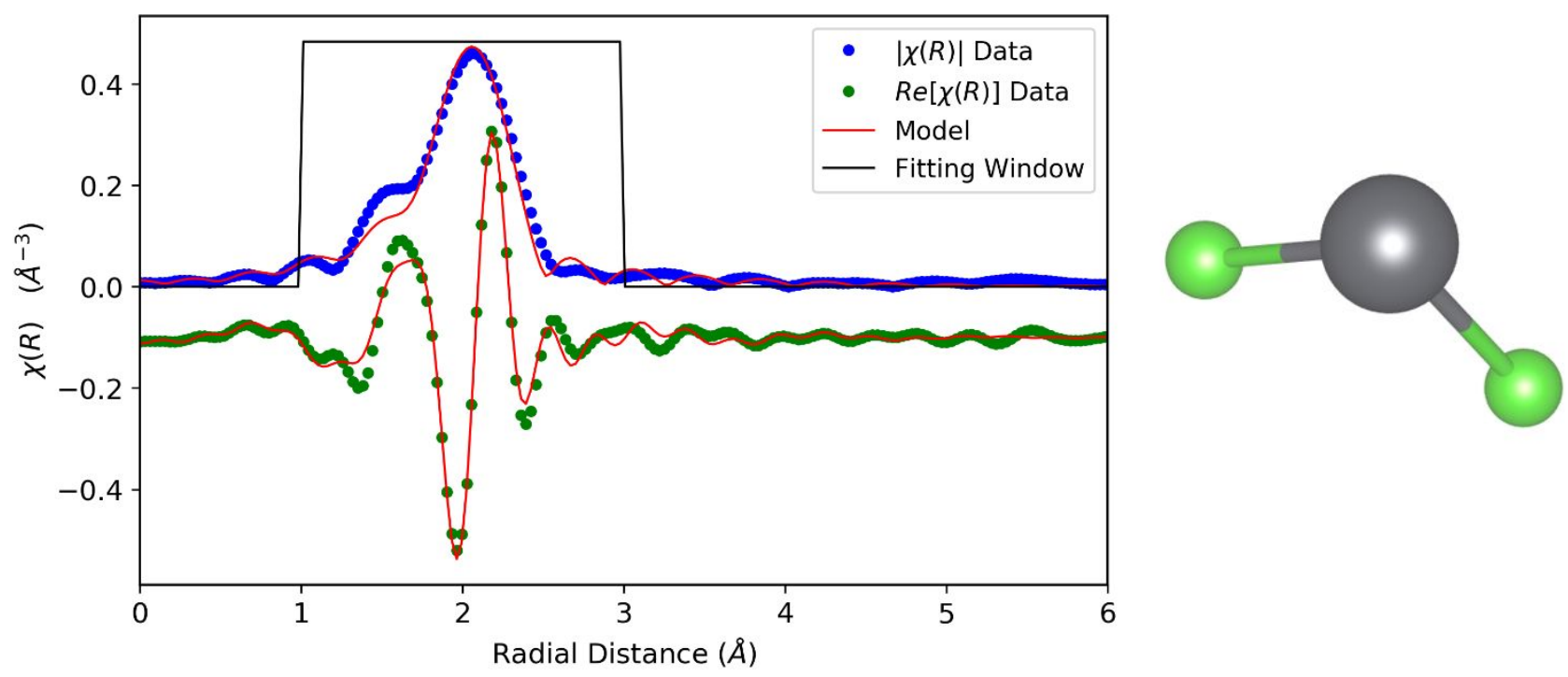

Figure S5 - Magnitude and real part of the Fourier transform of the $\mathrm{Pb} \mathrm{L}_{\mathrm{III}}$-EXAFS for $\mathrm{PbCl}_{2}$ dissolved in DMF (left) and schematic of local coordination of $\mathrm{Pb}$ species with $2 \mathrm{Cl}$ atoms (right).

\begin{tabular}{|c|c|c|c|c|c|c|c|}
\hline Coordinating Atom & $\mathrm{N}$ & $\mathrm{S}_{0}{ }^{2}$ & $\sigma^{2}$ & $\mathrm{E}_{0}$ & $\Delta \mathrm{R}$ & Reff & $\mathrm{R}$ \\
\hline $\mathrm{Cl1}$ & 2 & $0.73 \pm 0.18$ & $0.0046 \pm 0.0014$ & $-5.78 \pm 1.34$ & $-0.212 \pm 0.011$ & 2.784 & $2.571 \pm 0.011$ \\
\hline
\end{tabular}

EXAFS fitting summary:

k range: 3-11

Number of variables: 4

$\chi^{2}=3312.67$

$\chi_{\text {Reduced }}^{2}=557.92$

$\mathrm{R}$-factor $=0.0249$ 

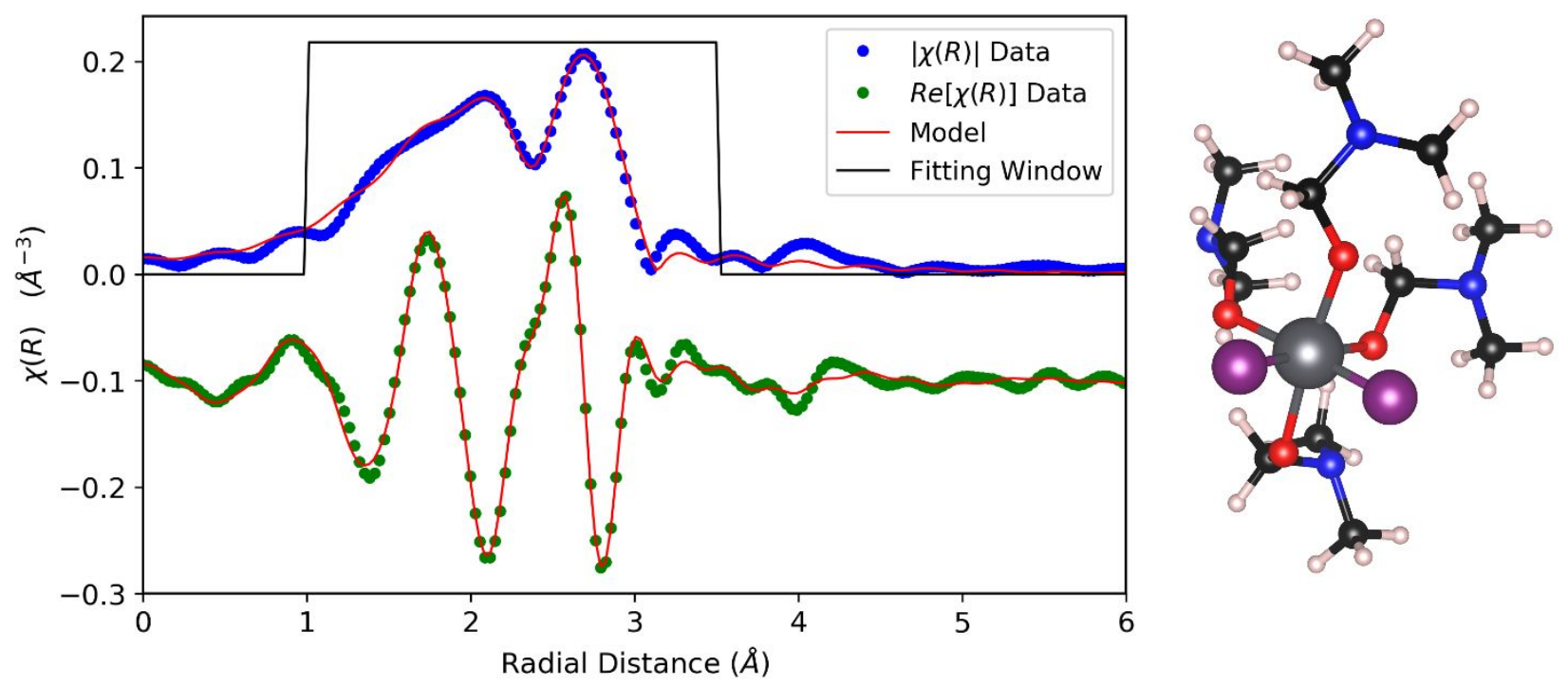

Figure S6 - Magnitude and real part of the Fourier transform of the $\mathrm{Pb} \mathrm{L}_{\mathrm{III}}$-EXAFS for $\mathrm{PbI}_{2}$ dissolved in DMF (left) and schematic of local coordination of $\mathrm{Pb}$ species with $2 \mathrm{I}$ atoms and $4 \mathrm{DMF}$ molecules (right).

\begin{tabular}{|c|c|c|c|c|c|c|c|}
\hline Coordinating Atom & $\mathrm{N}$ & $\mathrm{S}_{0}{ }^{2}$ & $\sigma^{2}$ & $\mathrm{E}_{0}$ & $\Delta \mathrm{R}$ & $\operatorname{Reff}$ & $\mathrm{R}$ \\
\hline $\mathrm{I} 1$ & 2 & $0.94 \pm 0.14$ & $0.0136 \pm 0.0014$ & $-5.81 \pm 1.03$ & $-0.235 \pm 0.010$ & 3.216 & $2.9810 \pm 0.010$ \\
\hline $\mathrm{O} 2$ & 4 & $0.845 \pm 0.34$ & $0.0307 \pm 0.0076$ & $-5.81 \pm 1.03$ & $0.012 \pm 0.026$ & 2.431 & $2.443 \pm 0.100$ \\
\hline
\end{tabular}

EXAFS fitting summary:

k range: $3-11$

Number of variables: 7

$\chi^{2}=458.11$

$\chi_{\text {Reduced }}^{2}=82.14$

$\mathrm{R}$-factor $=0.0108$ 


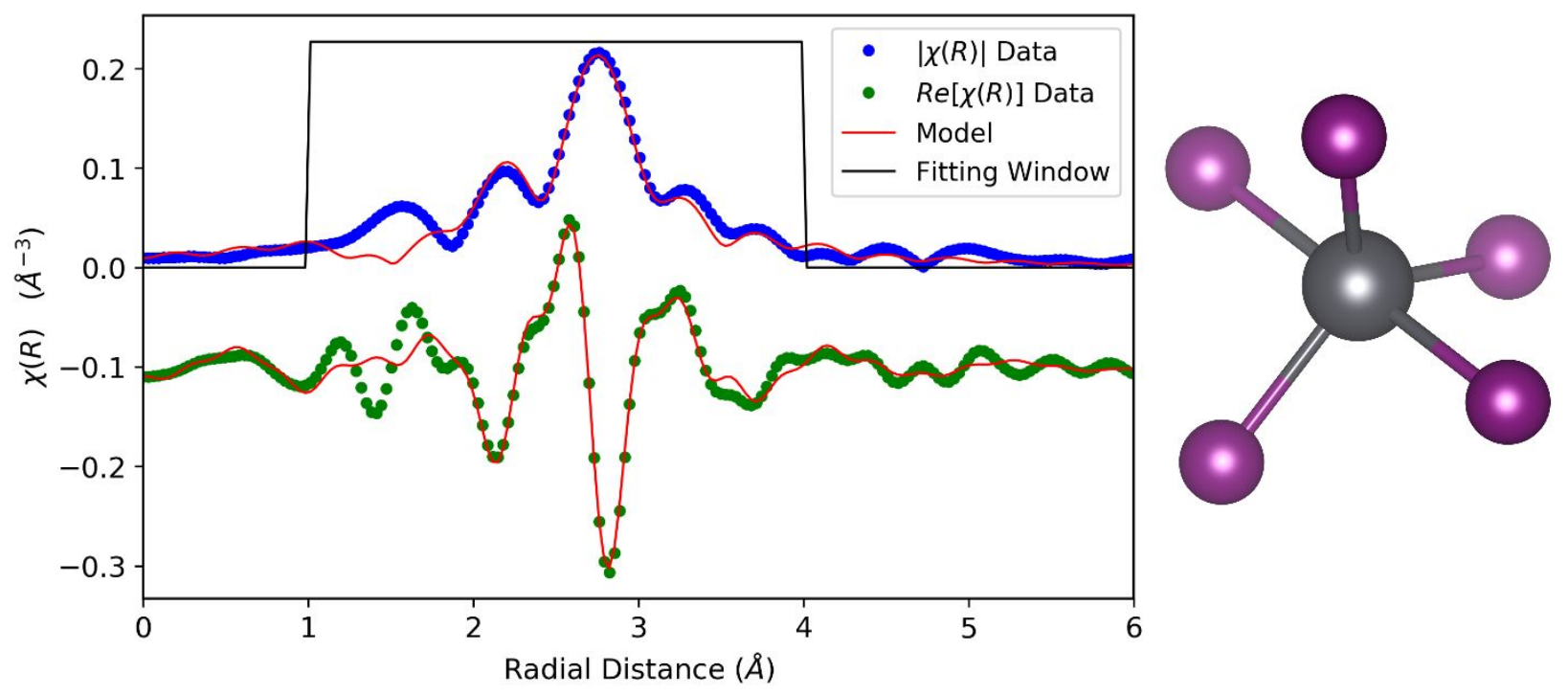

Figure S7 - Magnitude and real part of the Fourier transform of the $\mathrm{Pb} \mathrm{L}_{\mathrm{III}}-\mathrm{EXAFS}$ for $\mathrm{PbI}_{2}$ and MAI dissolved in a 3:1 molar ratio in DMF (left) and schematic of local coordination of $\mathrm{Pb}$ species with $5 \mathrm{I}$ atoms total (right). Note, there is likely some DMF solvation but is too poorly defined for inclusion in the EXAFS fitting.

\begin{tabular}{|c|c|c|c|c|c|c|c|}
\hline Coordinating Atom & $\mathrm{N}$ & $\mathrm{S}_{0}{ }^{2}$ & $\sigma^{2}$ & $\mathrm{E}_{0}$ & $\Delta \mathrm{R}$ & $\mathrm{Reff}$ & $\mathrm{R}$ \\
\hline $\mathrm{I} 1$ & 2 & 0.80 & $0.0101 \pm 0.0195$ & $3.22 \pm 2.47$ & $-0.140 \pm 0.187$ & 3.161 & $3.021 \pm 0.187$ \\
\hline $\mathrm{I} 2$ & 3 & 0.74 & $0.0171 \pm 0.0651$ & $3.22 \pm 2.47$ & $-0.066 \pm 0.449$ & 3.263 & $3.197 \pm 0.449$ \\
\hline
\end{tabular}

EXAFS fitting summary:

k range: 3-11

Number of variables: 7

$\chi^{2}=1109.56$

$\chi_{\text {Reduced }}^{2}=198.95$

$\mathrm{R}$-factor $=0.0693$

Note - the correlation between $\mathrm{S}_{0}^{2}$ for the two iodine paths is above $99 \%$, making meaningful determination of the uncertainty for these parameters impossible. 

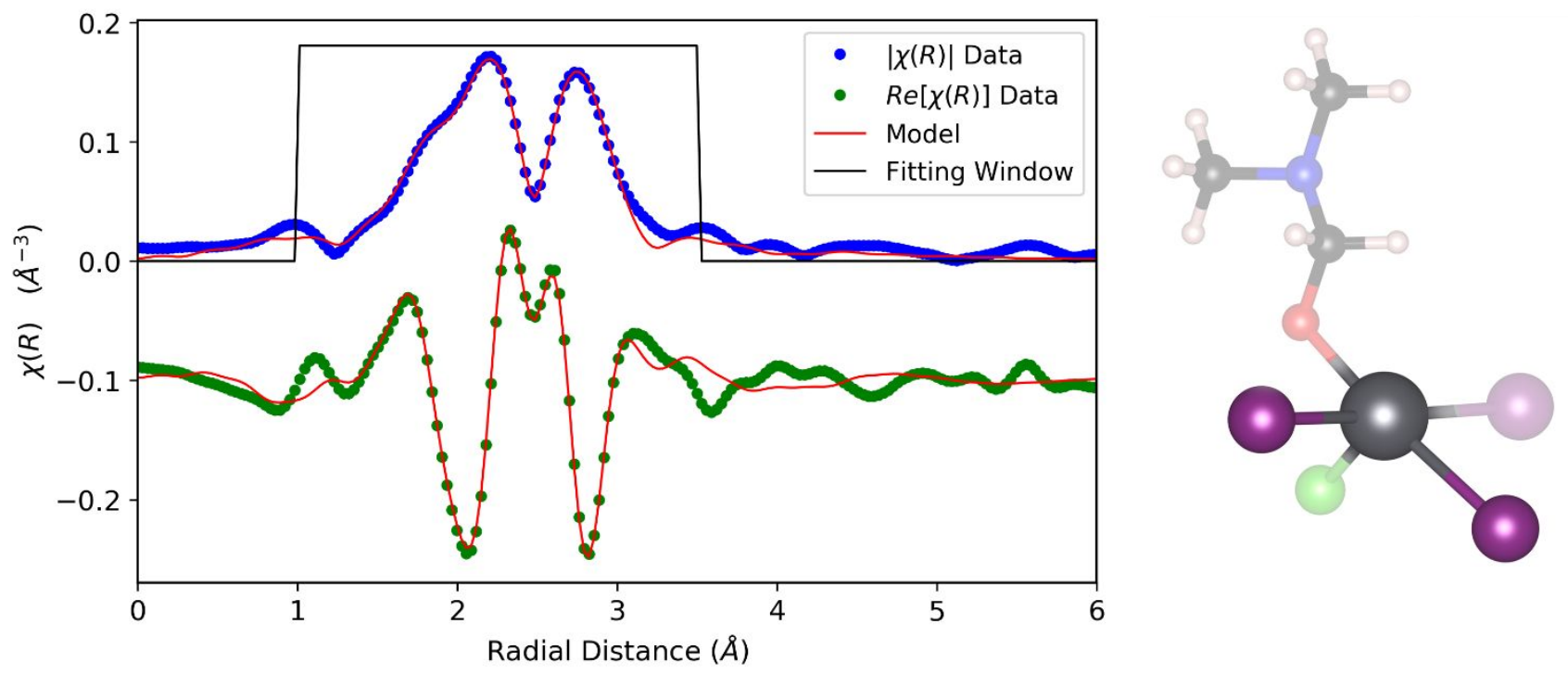

Figure S8 - Magnitude and real part of the Fourier transform of the $\mathrm{Pb} \mathrm{L}_{\mathrm{III}}$-EXAFS for $\mathrm{PbCl}_{2}$ and MAI dissolved in a 3:1 molar ratio in DMF (left) and schematic of local coordination of $\mathrm{Pb}$ species with $\sim 2.5 \mathrm{I}$ atoms, $\sim 0.33 \mathrm{Cl}$ atoms, and roughly half a DMF molecule (right). Note, partially occupied species are shown as partially transparent. Partial occupancy is a result of the volumetric averaging inherent to EXAFS such that, e.g., on average, $33 \%$ of $\mathrm{Pb}$ atoms are coordinated to a $\mathrm{Cl}$ atom.

\begin{tabular}{|c|c|c|c|c|c|c|c|}
\hline Coordinating Atom & $\mathrm{N}$ & $\mathrm{S}_{0}^{2}$ & $\sigma^{2}$ & $\mathrm{E}_{0}$ & $\Delta \mathrm{R}$ & $\mathrm{Reff}$ & $\mathrm{R}$ \\
\hline $\mathrm{C} 11$ & 0.33 & $0.837 \pm 0.641$ & $0.0040 \pm 0.00656$ & $-0.10 \pm 1.02$ & $-0.070 \pm 0.019$ & 2.784 & $2.714 \pm 0.019$ \\
\hline $\mathrm{I} 2$ & 2.5 & $0.831 \pm 0.195$ & $0.0177 \pm 0.0396$ & $-0.10 \pm 1.02$ & $-0.132 \pm 0.020$ & 3.161 & $3.029 \pm 0.020$ \\
\hline $\mathrm{O} 3$ & 0.4 & $0.842 \pm 0.683$ & $0.0098 \pm 0.0124$ & $-0.10 \pm 1.02$ & $-0.061 \pm 0.050$ & 2.431 & $2.370 \pm 0.050$ \\
\hline
\end{tabular}

EXAFS fitting summary:

k range: $2-12$

Number of variables: 10

$\chi^{2}=3058.67$

$\chi_{\text {Reduced }}^{2}=532.76$

$\mathrm{R}$-factor $=0.0224$ 
Structural refinements were performed using TOPAS-Academic. Structural models included a single lattice parameter, an independent isotropic thermal parameter for the $\mathrm{Pb}$-atom, anisotropic thermal parameters for the Iatom, and the methylammonium was modeled as a rigid body with a $\mathrm{C}-\mathrm{N}$ bond length of $1.48 \AA$ centered at fractional coordinates $(0.5,0.5,0.5)$ with rotations allowed to freely refine. A single isotropic thermal parameter was used for all methylammonium atoms. The positions and thermal parameters for the methylammonium are expected to be unreliable due to disorder.

Integrated diffraction patterns and corresponding fits are shown for the fully annealed films at $100^{\circ} \mathrm{C}$ roughly 5 minutes following full conversion to the perovskite phase. Allowed peak positions are shown as tick marks at the bottom of the plots. Crystal structures are shown with thermal ellipsoids at a 50\% level with methylammonium atoms removed for clarity. 

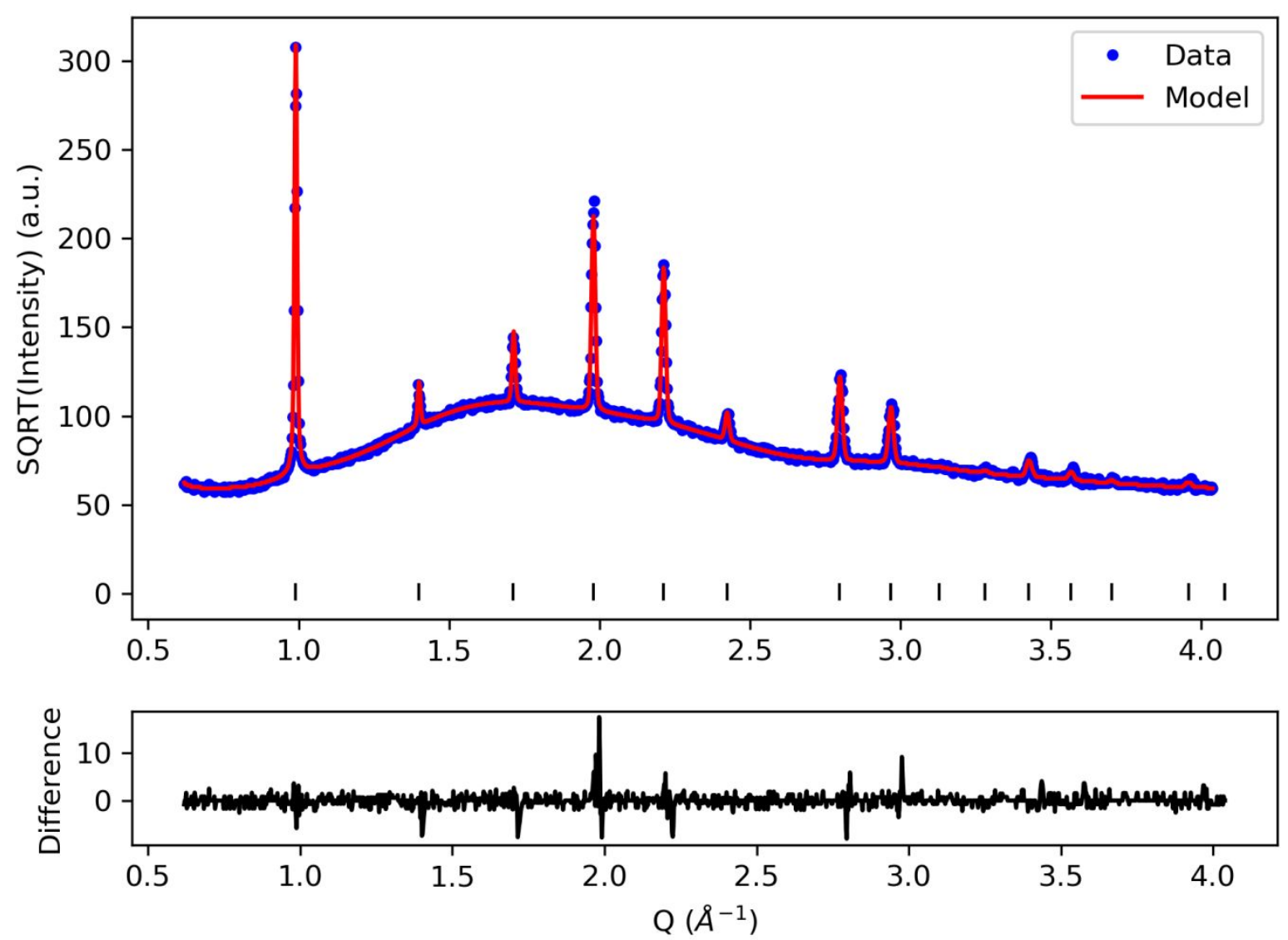

Figure S9 - Integrated X-ray diffraction data roughly 5 minutes after full conversion to the perovskite phase at $100^{\circ} \mathrm{C}$ from $3 \mathrm{MAI}+$ $\mathrm{PbCl}_{2}$ precursor solution. Data is shown in blue with the Rietveld refinement fit in red, difference is shown on expanded sale at bottom with tick marks indicating allowed peak positions.

\begin{tabular}{|c|c|}
\hline \multicolumn{2}{|l|}{ Crystal Data: } \\
\hline Space Group & Pm-3m \\
\hline $\mathrm{a}(\AA)$ & $6.3496(2)$ \\
\hline $\mathrm{V}\left(\AA^{3}\right)$ & $256.00(3)$ \\
\hline X-ray Wavelength & $0.9744 \AA$ \\
\hline $\mathrm{R}_{\mathrm{wp}}$ & 3.297 \\
\hline \multicolumn{2}{|l|}{ Atomic Parameters: } \\
\hline $\begin{array}{ll}\mathrm{Pb} & \text { Position } \\
& \text { Thermal Parameters }\end{array}$ & $\begin{array}{l}(0,0,0) \\
\mathrm{U}_{\text {iso }}=0.166(3)\end{array}$ \\
\hline $\begin{array}{ll}\text { I } & \text { Position } \\
& \text { Thermal Parameters }\end{array}$ & $\begin{array}{l}(1 / 2,0,0) \\
\mathrm{U}_{11}=0.117(4) \\
\mathrm{U}_{22}=\mathrm{U}_{33}=0.302(6) \\
\mathrm{U}_{12}=\mathrm{U}_{13}=\mathrm{U}_{23}=0\end{array}$ \\
\hline $\begin{array}{ll}\text { C } & \text { Position } \\
& \text { Thermal Parameters }\end{array}$ & $\begin{array}{l}(0.526,0.611,0.526) \\
\mathrm{U}_{\text {iso }}=0.2304(9)\end{array}$ \\
\hline $\begin{array}{ll}\mathrm{N} & \text { Position } \\
& \text { Thermal Parameters }\end{array}$ & $\begin{array}{l}(0.474,0.389,0.474) \\
U_{\text {iso }}=0.2304(9)\end{array}$ \\
\hline
\end{tabular}

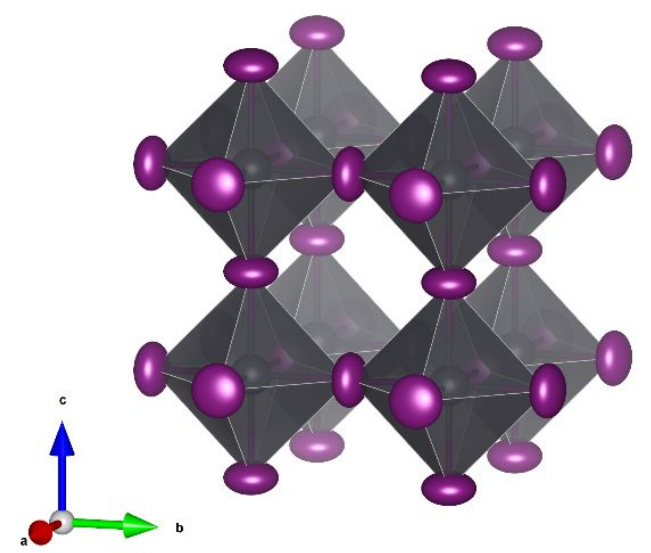



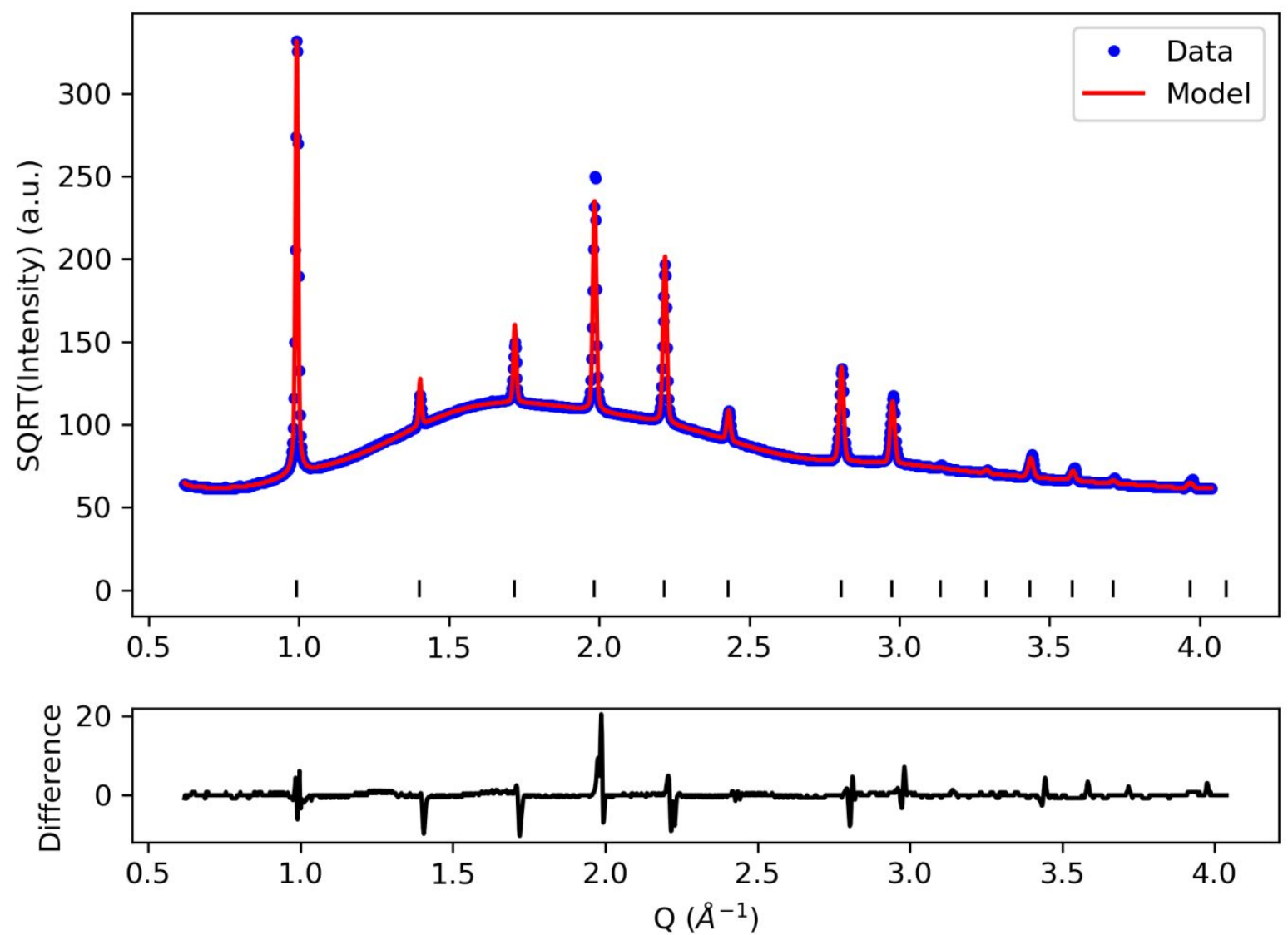

Figure S10 - Integrated X-ray diffraction data roughly 5 minutes after full conversion to the perovskite phase at $100^{\circ} \mathrm{C}$ from $2.5 \mathrm{MAI}+0.75 \mathrm{PbCl}_{2}+0.25 \mathrm{PbI}_{2}$ precursor solution. Data is shown in blue with the Rietveld refinement fit in red, difference is shown on expanded sale at bottom with tick marks indicating allowed peak positions.

\begin{tabular}{|c|c|}
\hline \multicolumn{2}{|l|}{ Crystal Data: } \\
\hline Space Group & Pm-3m \\
\hline $\mathrm{a}(\AA)$ & $6.3358(2)$ \\
\hline $\mathrm{V}\left(\AA^{3}\right)$ & $254.33(3)$ \\
\hline X-ray Wavelength & $0.9744 \AA$ \\
\hline $\mathrm{R}_{\mathrm{wp}}$ & 3.224 \\
\hline \multicolumn{2}{|l|}{ Atomic Parameters: } \\
\hline $\begin{array}{ll}\mathrm{Pb} & \text { Position } \\
& \text { Thermal Parameters }\end{array}$ & $\begin{array}{l}(0,0,0) \\
\mathrm{U}_{\text {iso }}=0.161(3)\end{array}$ \\
\hline $\begin{array}{ll}\text { I } & \text { Position } \\
& \text { Thermal Parameters }\end{array}$ & $\begin{array}{l}(1 / 2,0,0) \\
\mathrm{U}_{11}=0.1223(4) \\
\mathrm{U}_{22}=\mathrm{U}_{33}=0.291(5) \\
\mathrm{U}_{12}=\mathrm{U}_{13}=\mathrm{U}_{23}=0\end{array}$ \\
\hline $\begin{array}{ll}\text { C } & \text { Position } \\
& \text { Thermal Parameters }\end{array}$ & $\begin{array}{l}(0.587,0.578,0.498) \\
U_{\text {iso }}=0.214(3)\end{array}$ \\
\hline $\begin{array}{ll}\mathrm{N} & \text { Position } \\
& \text { Thermal Parameters }\end{array}$ & $\begin{array}{l}(0.413,0.422,0.502) \\
\mathrm{U}_{\text {iso }}=0.214(3)\end{array}$ \\
\hline
\end{tabular}

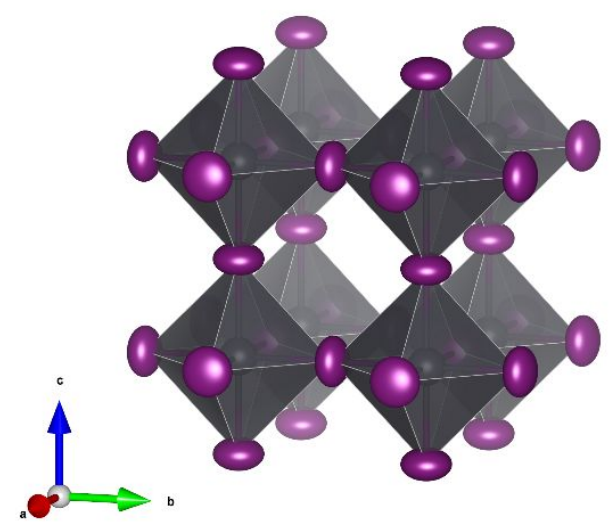



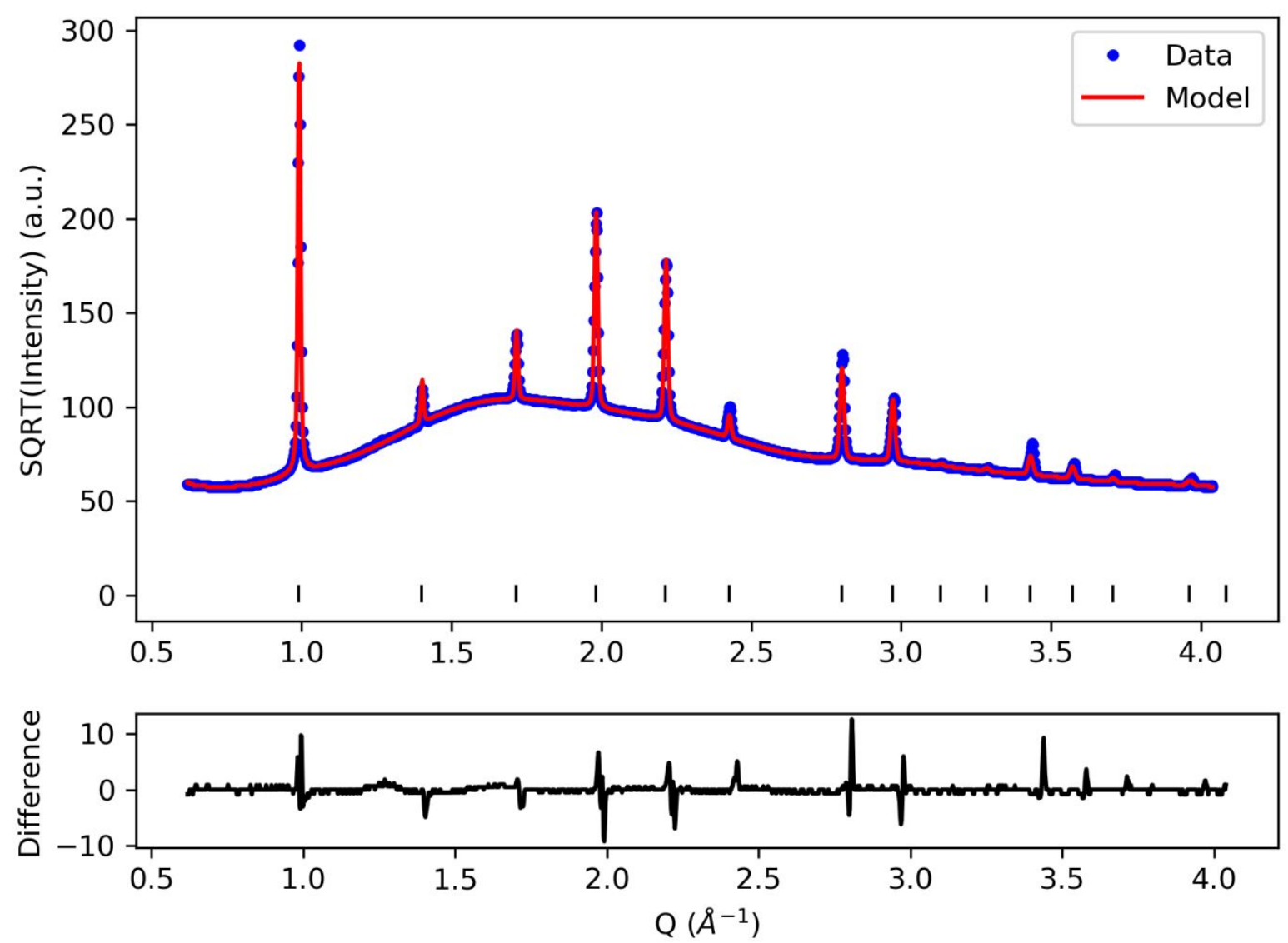

Figure S11 - Integrated X-ray diffraction data roughly 5 minutes after full conversion to the perovskite phase at $100^{\circ} \mathrm{C}$ from $2 \mathrm{MAI}$ $+0.5 \mathrm{PbCl}_{2}+0.5 \mathrm{PbI}_{2}$ precursor solution. Data is shown in blue with the Rietveld refinement fit in red, difference is shown on expanded sale at bottom with tick marks indicating allowed peak positions.

\begin{tabular}{|c|c|}
\hline \multicolumn{2}{|l|}{ Crystal Data: } \\
\hline Space Group & Pm-3m \\
\hline $\mathrm{a}(\AA)$ & $6.3445(2)$ \\
\hline $\mathrm{V}\left(\AA^{3}\right)$ & $255.39(3)$ \\
\hline X-ray Wavelength & $0.9744 \AA$ \\
\hline $\mathrm{R}_{\mathrm{wp}}$ & 2.831 \\
\hline \multicolumn{2}{|l|}{ Atomic Parameters: } \\
\hline $\begin{array}{ll}\mathrm{Pb} & \text { Position } \\
& \text { Thermal Parameters }\end{array}$ & $\begin{array}{l}(0,0,0) \\
\mathrm{U}_{\text {iso }}=0.152(3)\end{array}$ \\
\hline $\begin{array}{ll}\text { I } & \text { Position } \\
& \text { Thermal Parameters }\end{array}$ & $\begin{array}{l}(1 / 2,0,0) \\
\mathrm{U}_{11}=0.147(4) \\
\mathrm{U}_{22}=\mathrm{U}_{33}=0.268(5) \\
\mathrm{U}_{12}=\mathrm{U}_{13}=\mathrm{U}_{23}=0\end{array}$ \\
\hline $\begin{array}{ll}\text { C } & \text { Position } \\
& \text { Thermal Parameters }\end{array}$ & $\begin{array}{l}(0.550,0.602,0.525) \\
U_{\text {iso }}=0.253(3)\end{array}$ \\
\hline $\begin{array}{ll}\mathrm{N} & \text { Position } \\
& \text { Thermal Parameters } \\
\end{array}$ & $\begin{array}{l}(0.450,0.398,0.475) \\
U_{\text {iso }}=0.253(3)\end{array}$ \\
\hline
\end{tabular}

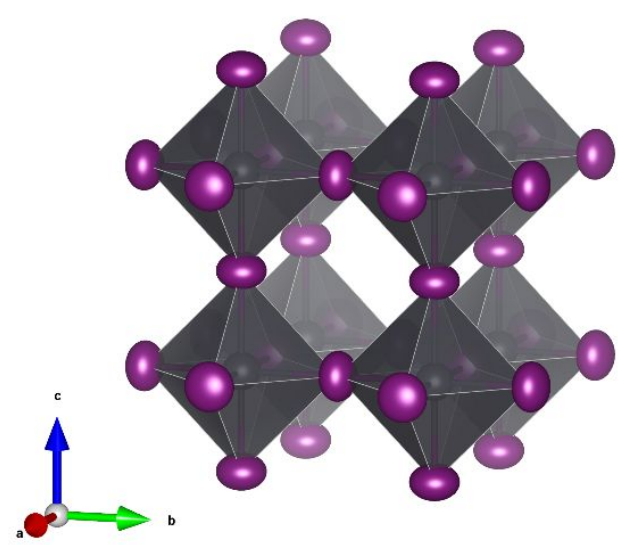

